Check for updates

1 University of Southampton

2 University Hospital Southampton NHS Foundation Trust

N.A.Alwan@soton.ac.uk Follow Nisreen on Twitter @Dr2NisreenAlwan Cite this as: BMJ 2021;375:n2641 http://dx.doi.org/10.1136/bmj.n2641 Published: 29 October 2021

\section{We must call out childism in covid-19 policies}

\section{Nisreen A Alwan questions whether the current rates of covid infection in UK school children are acceptable when we have emerging evidence of the virus's lingering health effects}

\author{
Nisreen A Alwan associate professor in public health and honorary consultant of public health ${ }^{1,2}$
}

I recently wrote on Twitter ${ }^{1}$ in reference to the current SARS-CoV-2 child infection rates in England: "It really isn't fair how covid is allowed to spread so uncontrollably in school-aged kids. I feel like a broken record, but I can't stop saying this. Kids paid such a high price to protect the adults in the first year of the pandemic and now the adults don't seem to care. Not fair."

Childism is a term that has been used to describe institutional prejudice and systemic injustice against children, ${ }^{2}$ as observed during the pandemic in policy decisions. Adami and Dineen critique the language that describes children as "vectors of transmission," as well as the effect of school closures, and policies that exacerbate child hunger and compromise their safety. I'd argue that allowing mass SARS-CoV-2 infections among children is also a form of childism.

The latest data from the Office for National Statistics (ONS) on infection prevalence in England 3 show that $7.8 \%$ of secondary school aged children (school year 7 to 11 ) and $3.8 \%$ of those aged 2 to school year 6 had covid-19 during the week ending 16 October 2021. Children had by far the highest infection rates among all age groups, followed by those in the parent age bracket of 35-49 years (1.5\%). The rates of hospital admissions during the week ending 17 October 2021 per 100 ooo people were 2.9 for ages $0-4,1.8$ for ages 5-14, and 1.9 for ages 15-24. These are much lower than covid-19 admission rates for older age groups. However, worryingly, hospital admissions for children aged 5-14 were $74 \%$ higher ${ }^{3}$ compared with January 2021 at the peak of the UK's second coronavirus wave. What these infection rates mean in terms of children's education is that 209000 state school pupils in England (2.6\%) were not in school due to coronavirus-related reasons on 14 October 2021, including 111000 with confirmed infection. ${ }^{4}$

Are such rates of coronavirus infection in the young acceptable? This is a virus that is constantly evolving into new variants and which results in prolonged ill health in some of those infected. The latest UK figures from the ONS on long covid ${ }^{5}$ released on 7 October 2021 estimate that 11 ooo children aged 2-16 have it for at least a year from the date of confirmed or probable infection, with 29000 estimated not to have recovered at least 12 weeks after onset. This equates to about one in 1000 children out of all those aged 2-11 years living in private households in the UK and five in 1000 out of 12-16-year-olds. ${ }^{5}$

Debate around the definition and methods of estimation of long covid is valid, but it must not detract from the fact that a proportion of children are not recovering after infection, and the higher the community infection rate, the higher the number of children experiencing longer term effects. Long covid does not only affect children's physical health, but also disrupts their education, causes social isolation, and may lead to declining mental health-all of which are likely to contribute to longer term inequalities. We need to stop propagating a false dichotomy that pitches children's education and wellbeing against efforts to reduce community transmission of SARS-CoV-2. Socioeconomic and demographic disadvantage must not be compounded with further health inequalities due to SARS-CoV-2 infection.

Autzen et al argue that childism may also be at play when it comes to debates on covid-19 vaccines. They point out that we must be wary of calls to deprioritise children for vaccines ${ }^{6}$ when they betray a bias towards adults in their reasoning. For example, the argument that immunity after infection may be sufficient in children, while adults are recommended to get vaccinated regardless of previous infection.

The UK's Medicines and Healthcare products Regulatory Agency concluded that the Pfizer/BioNTech covid-19 vaccine is safe and effective in the 12-15 age group on 4 June 2021. ${ }^{7}$ It was good news at the time because we had an opportunity during the summer holiday to offer teenagers the vaccine before the autumn term, when they would start mixing in schools again. However, a decision from the Joint Committee on Vaccination and Immunisation (JCVI) on universal roll-out remained eagerly awaited. Eventually, a statement on 3 September said that in JCVI's assessment "the margin of benefit is considered too small to support universal vaccination of healthy 12 to 15 year olds." 8 This was when many other countries had already vaccinated millions of children in that age group. ${ }^{9}$ The decision to offer universal vaccination to this age group was delayed until the UK's chief medical officers released their advice to the government on 13 September. ${ }^{10}$ However, currently only one dose out of the two dose vaccination course is offered universally to this age group. ${ }^{11}$

My plea to acknowledge the uncertainties around mass infection in children is not "alarmism" or a call for panic, as such concerns have been often labelled. What I am doing is rejecting the abandonment of the precautionary principle when it comes to a virus that we still know relatively little about, with emerging evidence of worrying lingering health effects. ${ }^{12}$ In addition, with re-infections becoming more common, ${ }^{13}$ the theoretical assumption that immunity after high levels of natural infection in children will end the pandemic ${ }^{14}$ is questionable.

I am certainly not calling for school closures or further lockdowns. I fully recognise that prolonged 
school closures can have damaging public health, social, and educational effects on children. However, there are effective protective measures ${ }^{15}$ that can be used to keep children attending school and to avoid lockdowns. In addition to the full course of vaccination, these include adequate ventilation, face masks indoors, and reduced crowding. ${ }^{16}$ Children have had their education disrupted, their social lives restricted, and their mental health-and sometimes safety-compromised to save adults. Now that adults are more protected, children should not be left to face mass infection with the very same virus they made sacrifices to protect adults from.

Acknowledgment: Nisreen A Alwan is a mother of three children and has lived experience of long covid.

Competing interests: none declared.

1 Nisreen A. Alwan. Twitter. October 2021. https://twitter.com/Dr2NisreenAlwan/status/1450479044336754695?s=20

2 Adami R, Dineen K. Discourses of childism: how covid-19 has unveiled prejudice, discrimination and social injustice against children in the everyday. Int J Child Rights 2021;29:353-70. doi: 10.1163/15718182-29020001.

3 Office for National Statistics. Coronavirus (COVID-19) latest insights: Hospitals. 29 October 2021. https://www.ons.gov.uk/peoplepopulationandcommunity/healthandsocialcare/conditionsanddiseases/articles/coronaviruscovid19latestinsights/hospitals\#hospital-admissions-by-age.

$4 \quad$ UK government. Attendance in education and early years settings during the coronavirus (COVID-19) pandemic. 19 October 2021. https://explore-education-statistics.service.gov.uk/findstatistics/attendance-in-education-and-early-years-settings-during-the-coronavirus-covid-19outbreak/2021-week-42

5 Office for National Statistics. Prevalence of ongoing symptoms following coronavirus (COVID-19) infection in the UK. 7 October 2021. https://www.ons.gov.uk/peoplepopulationandcommunity/healthandsocialcare/conditionsanddiseases/datasets/alldatarelatingtoprevalenceofongoingsymptomsfollowingcoronaviruscovid19infectionintheuk

6 Autzen B, Dineen K, Vaughan D. Vaccinating children: fairness and childism. Lancet Infect Dis 2021;21:1354-5. doi: 10.1016/S1473-3099(21)00483-7. pmid: 34399089

7 UK government. The MHRA concludes positive safety profile for Pfizer/BioNTech vaccine in 12 to 15-year-olds. 4 June 2021. https://www.gov.uk/government/news/the-mhra-concludes-positivesafety-profile-for-pfizerbiontech-vaccine-in-12-to-15-year-olds

8 UK government. JCVI issues updated advice on COVID-19 vaccination of children aged 12 to 15. 3 September 2021. https://www.gov.uk/government/news/jcvi-issues-updated-advice-on-covid19-vaccination-of-children-aged-12-to-15

9 Reed J. Covid: Which countries are vaccinating children and why? BBC News. 14 September 2021. https://www.bbc.co.uk/news/health-58516207

10 Chris Whitty says children aged 12 to 15 to be offered Covid jab - video. The Guardian. 13 September 2021. https://www.theguardian.com/uk-news/video/2021/sep/13/chris-whitty-sayschildren-aged-12-to-15-to-be-offered-covid-jab-video

11 NHS website. Coronavirus (COVID-19) vaccine for children aged 12 to 15. https://www.nhs.uk/conditions/coronavirus-covid-19/coronavirus-vaccination/coronavirus-vaccinefor-children-aged-12-to-15/

12 Roessler M, Tesch F, Batram M. Post COVID-19 in children, adolescents, and adults: results of a matched cohort study including more than 150000 individuals with COVID-19.medRxiv 2021 [Preprint]. https://www.medrxiv.org/content/10.1101/2021.10.21.21265133v1

13 Geddes L. Without Covid-19 jab, "reinfection may occur every 16 months." The Guardian. 19 October 2021. https://www.theguardian.com/world/2021/oct/19/without-covid-19-jab-reinfectionmay-occur-every-16-months-say-scientists

14 Morgan E. Covid cases "could drop within month without need for Plan B," scientists say. ITV News. 25 October 2021. https://www.itv.com/news/2021-10-25/covid-cases-could-drop-withinmonth-without-need-for-plan-b-scientists-say

15 Gettings J, Czarnik M, Morris E, etal. Mask Use and Ventilation Improvements to Reduce COVID-19 Incidence in Elementary Schools - Georgia, November 16-December 11, 2020. MMWR Morb Mortal Wkly Rep 2021;70:779-84. doi: 10.15585/mmwr.mm7021e1. pmid: 34043610

16 Gurdasani D, Alwan NA, Greenhalgh T, etal. School reopening without robust COVID-19 mitigation risks accelerating the pandemic. Lancet 2021;397:1177-8. doi: 10.1016/S0140-6736(21)00622-X. pmid: 33713595 